\title{
Talking to the parents of a baby who is likely to develop permanent neurological impairment following a brain insult in the perinatal period
}

\author{
Steven Ryan
}

\begin{tabular}{|l|}
\hline $\begin{array}{l}\text { Acquired conditions } \\
\text { causing perinatal brain } \\
\text { injury }\end{array}$ \\
\hline - intrapartum asphyxia, eg, placental \\
abruption, ruptured uterus, cord \\
prolapse \\
- preterm infants: intraventricular \\
haemorrhage, periventricular \\
leukomalacia \\
- kernicterus \\
- intraceritis \\
vascular malformation, \\
coagulopathy \\
- trauma \\
- encephalitis, eg, cytomegalovirus \\
\hline
\end{tabular}

Box 1

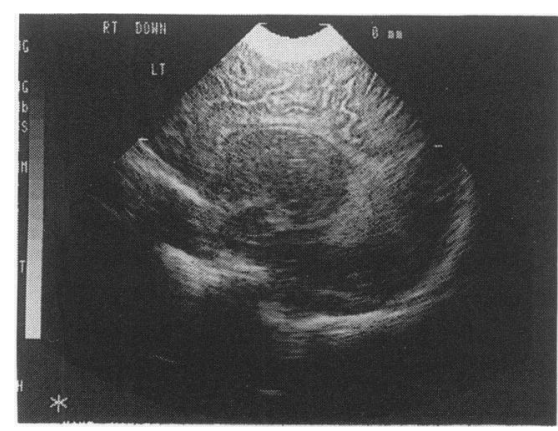

Figure 1 Parasaggital cranial ultrasound of fullterm neonate with enhanced gyral pattern and slit-like lateral ventricle, due to cerebral oedema

Keywords: communication skills, education, perinatal brain insult, neurological damage

Institute of Child Health, Royal

Liverpool Children's Hospital,

Liverpool L12 2AP, UK

S Ryan

Accepted 15 February 1995

\section{What brain insults occur?}

In most children who develop a neurological impairment in childhood, there is no acute perinatal illness. Although Little assumed that most cerebral palsy was due to birth asphyxia, ${ }^{1}$ we now know that probably less than $10 \%$ of cases result from such asphyxia. However, in any reasonably sized maternity unit, there will be several babies born each year with acute disorders of the brain who are at risk of long-term impairment.

The commonest disorders encountered are hypoxic-ischaemic encephalopathy, most commonly seen in full term neonates, and intraventricular haemorrhage and periventricular leucomalacia in preterm neonates. Because these conditions are relatively common, relatively large series of cases have been reported, establishing the relationship between the severity of the initial illness and long-term outcome. Using this information it becomes possible to give the parents some idea of their child's likely outcome. Other rarer causes of brain insult in the perinatal period are kernicterus (hyperbilirubinaemic encephalopathy) and meningitis (box 1).

\section{HYPOXIC-ISCHAEMIC ENCEPHALOPATHY}

Clinically, hypoxic-ischaemic encephalopathy (figure 1) has been divided into three grades and this grading system is now widely used. Levene et al showed that neonates with mild encephalopathy (no seizures) had virtually no risk of long-term disability, those with moderate encephalopathy had a risk of about $25 \%$ of dying or having a severe disability and those with severe encephalopathy had a risk between $50 \%$ and $100 \%$ of a similar outcome. Other features which are associated with high risk of adverse outcome are delayed onset of spontaneous respiration beyond 20 minutes, a delay in feeding beyond the age of a week and a persisting abnormal neurological status in the newborn period. In infants suffering a cardiac arrest at birth, all survivors not breathing spontaneously at 30 minutes developed spastic quadriplegia. ${ }^{3}$ In another study $75 \%$ of infants not breathing spontaneously by 20 minutes after birth either died or had severe neurological impairment. ${ }^{4}$

Persisting hypotonia or hypotonia rapidly evolving to extensor hypertonia is associated with a high incidence $(>75 \%)$ of either death or handicap. ${ }^{2}$ In many infants, however, particularly in the group with moderate encephalopathy, there is a honeymoon period of several months when the infant appears to have no or little neurological abnormality. In this situation it is wise to be cautious. In most infants by one year of age any abnormality, most usually cerebral palsy, will reveal itself. In general, the earlier the abnormality is detected, the more severe the resulting impairment.

\section{INTRAVENTRICULAR HAEMORRHAGE}

Intraventricular haemorrhage arises in preterm neonates from the germinal matrix lying bilaterally in the floor of the body of the lateral ventricle next to the head of the caudate nucleus. Haemorrhage may be confined to the matrix (Grade I; figure 2), in which case impairment is unlikely. If the haemorrhage ruptures into the ventricle itself (Grade II; figure 3), this may cause obstruction to flow of cerebrospinal fluid - post-haemorrhagic hydrocephalus (figure 4), or local parenchymal infarction (figure 3 ). In either of these situations, there is a high risk of long-term impairment, cerebral palsy being common..$^{5}$ If an infant requires treatment for post-haemorrhagic ventricular dilatation in the newborn period, there is a $90 \%$ risk of neuromotor impairment which results in $76 \%$ of survivors having a marked disability. ${ }^{5}$ Other impairments include deficits in vision, 


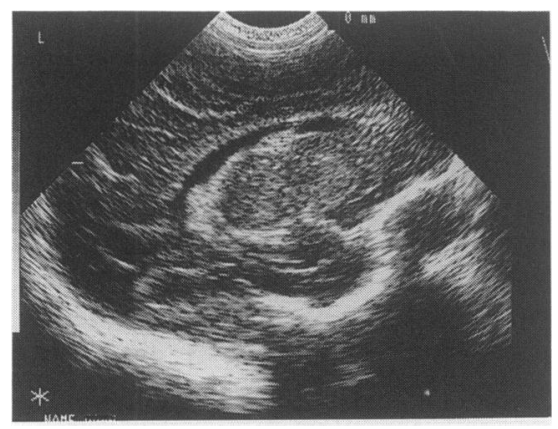

Figure 2 Left sided parasaggital cranial ultrasound scan of preterm infant showing sub-ependymal haemorrhage as echodensity on floor of body of lateral ventricle

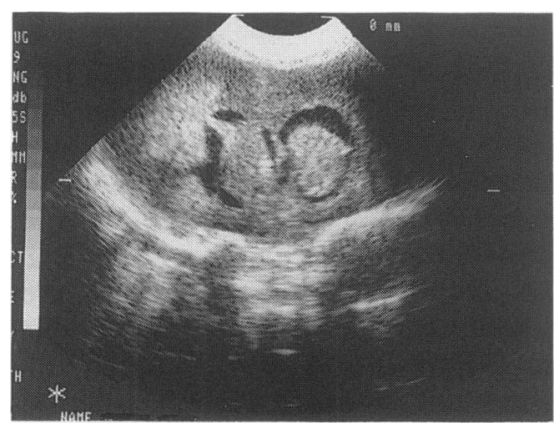

Figure 3 Coronal cranial ultrasound through anterior fossa of preterm neonate showing bilateral echodense clots within dilated anterior horns of both lateral ventricles. On one side venous infarction has led to an echodensity within the parenchyma

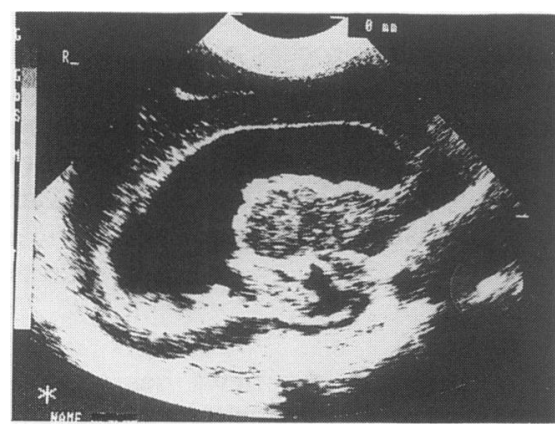

Figure 4 Parasaggital cranial ultrasound scan in preterm neonate showing posthaemorrhagic ventricular dilatation

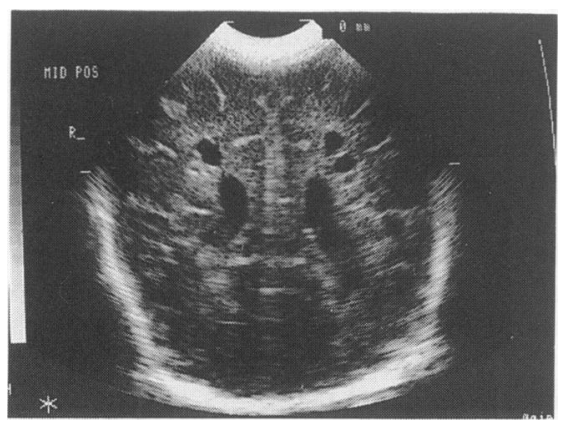

Figure 5 Posterior coronal cranial ultrasound scan in preterm neonate showing bilateral occipital cystic leukomalacia. This appearance is strongly correlated with severe multiple neurological disability hearing and intellect. Bilateral lesions have a greater association with severe impairments. All haemorrhagic lesions are easily identified by cranial ultrasound in the neonatal period. ${ }^{6}$

Ischaemic lesions in preterm infants occur in the periventricular area, which is the vascular watershed at low gestations. Lesions occur in up to $5 \%$ of preterm neonates $<32$ weeks gestation. Significant lesions are usually bilateral and result in 'punched-out' cystic lesions seen on cranial ultrasound ${ }^{6}$ (figure 5) above and lateral to the ventricles. Cerebral palsy is frequently seen, since the internal capsules pass through this area. Diplegia is more commonly seen than quadriplegia. $^{7}$

\section{Withdrawing care?}

It is obviously possible to identify some infants in the first days who are at very high risk of death or severe handicap. If such infants are receiving intensive care, it may be appropriate to consider withdrawing it. This situation will not be discussed further in this article except to say that the final decision must be taken by the senior clinician in charge of the patient's care. The situation must be explained to the parents and they must understand and accept the decision before it is enacted. However, the parents must not feel that they were responsible for making the choice. It is not within the scope of this article to discuss the ethics underlying such a decision.

\section{What do parents want to know?}

Parents want to know what has happened, why it has happened and what it means for the future of their child? In explaining what has happened, simple terms such as brain damage are acceptable, particularly if the parents understand and use the term. There is always the temptation for doctors to give a large amount of technical medical detail, quite often at a level we would not expect medical students to comprehend fully! If there are any scan images, show them to the infant's parents, since this helps get your message over. If possible, have a normal scan available for comparison. Scan images are most helpful for haemorrhagic lesions in preterm neonates, as ultrasound images in babies with even severe encephalopathy can be normal or exhibit subtle changes (figure 1).

An explanation of the reasons for their child's predicament will be high on the parents' agenda. They will need to know if anything could have been done differently which would have prevented the situation. Brain lesions in preterm infants arise as a consequence of prematurity. There is little evidence to suggest that avoidable obstetric factors have any influence on the incidence of these problems.

The parents of an infant who appears to have suffered intra-partum birth asphyxia, may be very concerned to find out if any such factors existed. It is said that inadequacy in dealing with such questions and failure to apologise if an inadequacy has occurred are the root of much litigation. So the issue must be addressed. Ideally the obstetrician in charge of the mother's care should address such issues as soon as possible, answering all of the parents' questions. He or she should be aware of what the parents have been told by the paediatrician.

Paediatricians should be aware, however, that some babies who appear asphyxiated are not. Babies may have developed or acquired an abnormality of the central nervous system before labour. Such babies can present with all the classical features of intrapartum asphyxia because their ability to react to the stressful event of labour is impaired. Abnormal cardiotocograms, meconiumstained liquor, depressed Apgar score and neonatal encephalopathy have all been described in such infants. ${ }^{8,9}$ Of course, their abnormal central nervous system results in future neurological impairment. Hence the term birth asphyxia should be used with caution. In the first instance, a purely descriptive 'label' of features present should be attached. If necessary, this concept should be explained to the parents.

Having established that a disorder has arisen, the parents will want to know what this means for the future of their child. They would like an accurate picture but unfortunately this is not always possible. For instance in a fullterm neonate who has suffered moderately severe hypoxic-ischaemic encephalopathy, the average risk of severe problems is $25 \%$. The problem is that it is impossible to know for the individual child, whether he or she is in that $25 \%$ or the other $75 \%$. Rather than hazarding a guess, it is important to explain this uncertainty. If you can show that you are 'confident' about this uncertainty and you are familiar with up-to-date opinion, you can still develop a trusting relationship with the parents. It is alright to say ' $I$ do not know'. 
One useful way of getting the message over is by referring to a range of potential disabilities; an equivalent, say, to a confidence interval between the 5 th and 95th centile. Here you can set out for the parents the nature of the best and worst outcomes they could expect. For instance the child who has suffered moderately severe hypoxic-ischaemic encephalopathy has one goal post which is normality and another which represents spastic quadriplegia and severe compromise of future lifestyle. It is wise to avoid, at this stage of uncertainty, specific statements about likely function. If asked 'Will he walk?' in the above scenario, you can return to the range of disabilities you have predicted as potential outcomes. There is evidence that even accurate statements, if given in a pessimistic context, give rise to anger, which can be lifelong, eg 'your child will never read or write' ${ }^{10}$ Here the idea of a range is useful as it gives the parents some target to aim for and allows some optimism.

The lack of specificity should be accompanied by some idea of when you are likely to be more certain and what follow-up you intend. By the age of nine months to a year, most cerebral palsy will have revealed itself.

\section{Breaking the news}

In many ways delivering news of a likely or impending handicap is like telling relatives that a family member has died. The parents will have had some image of how their normal child was going to live. This loss of that potential provokes a grief reaction which can be as intense as that seen in a bereavement. Similar skills, facilities, and resources to those needed when imparting the news of a death are required. The parent's experience at the initial informing interview can play an important role in the family's perception of the child and their long-term adjustment to the child's disability. ${ }^{11}$ Consequently, it is not only important what is communicated, but how it is communicated.

If possible, parents should be told together. They should be told as soon as a likely problem is identified, sympathetically and without jargon. ${ }^{10}$ Parents appreciate being told directly in a clear straightforward way but including positive images of their child (boxes $2-4) .{ }^{10}$

\section{Understand nature of parental reaction}

- familiar to parent

- already knows child

- appears comfortable

- equal not superior

- supportive

\section{Box 2}

\begin{tabular}{|l|}
\hline What information parents \\
want \\
\hline - co-ordinated \\
- clear \\
- includes positive characteristics \\
- addresses future questions \\
- resources available \\
share diagnostic features (scans, \\
\hline
\end{tabular}

Box 3

\section{How parents want to be told}

Delivery

- direct

- caring, compassionate

- information personalised

- gradual - paced, not hurried

Situation

- private and quiet

- face to face (not telephone)

- parents together, with supporters

- baby present

- parents have already spent time with baby

Box 4
The parent's reaction can be very intense and can include inappropriate feelings of anxiety, guilt or blame. Firstly, the parents should be told that these reactions are normal human emotional reactions to such a situation. Secondly, it is necessary to allay these inappropriate feelings. This process may have to be repeated several times. By knowing the nature of the reaction, the medical team can be prepared and know that it is not their actions in breaking the news which have been the cause of such feelings. It will also make them aware that the parents may feel anger and blame and direct it at their child's carers. In some senses an obvious emotional reaction is a sign that the message has got across.

\section{Setting up the interview}

Having the infant's nurse with you when you break the news has several advantages. Firstly, support for yourself and secondly in ensuring a consistent message to the parents. It is helpful to brief the nurse prior to the interview to explain the main points you wish to raise. He or she may also be able to retain some of the parents' questions which they overlook. The nurse will also be able to reiterate the main messages until the next interview and log any further questions the parents may have. The nurse can also translate any medical jargon inadvertently used. A junior medical colleague can also perform many of the same roles and will also obtain useful training. By asking the nurse or medical colleague about what they thought you did well and what they would have done differently, the interviewer can gain valuable insight into his or her own technique. In this situation it is important to avoid negative feedback, as this can itself be distressing in such circumstances.

Following the interview a comprehensive medical note should be written. This serves as an important communication for other health care workers and helps to ensure a consistent message. The nurse should also record his or her perceptions in the nursing cardex.

Parents appreciate privacy and time when being given bad news, and up to 45 minutes should be allowed for the first session. A frequent reaction to the delivery of the news is stunned silence, or crying. One's natural instinct at this point is to try and break the silence or perhaps leave. Another approach is to remain silent and wait for the parents to ask you the next question. This rarely takes more than one or two minutes. At this time the parents will hardly seem to 
notice your presence and in hindsight they frequently comment that knowing the doctor was still available was helpful. Having the baby present with you at the time is helpful, but this may not be possible if the baby is unwell and on a busy special care unit.

The first interview should be the start of a number of interviews, which are arranged at the time of the first interview. These secondary interviews should have the format of the first, but concentrate even more on answering the parents questions and checking they have understood the main concepts. Occasionally, due to unforseen circumstances, another doctor may be asked to undertake an interview, possibly requested at short notice by the parents. In this situation a review of the nursing and medical notes and open questions to the parents about their current understanding will usually allow a successful interview.

Parents appreciate a doctor who is empathic, who listens and who seems to understand them. ${ }^{10}$ This appreciation can be fostered by such simple methods as furniture placement and posture, and knowledge of other basic communication skills. ${ }^{11}$ Not the cold distant upright figure the other side of a desk, but the doctor sitting with the parents, sitting forward attentively. There is some question about the degree of physical contact. A hug? A handshake? A hand on the shoulder? There is no set way. Do what you feel comfortable with.

At some point during the interviews, tell the parents that you do not mind them bringing written questions, since it will aid their memory of and understanding of any points which you make.

\section{Cerebral palsy}

The most frequent adverse outcome in survivors of neonatal brain disorders is cerebral palsy. Since the definition of the condition continues to be debated, great care is required when informing the parents about the condition. The parents may have their own idea about what constitutes cerebral palsy, so before the interviewer describes the condition, the parents should be asked what they understand by the term. If they have a fair idea, this will aid communication. If their knowledge is false or unrealistic, finding out at this stage will enable the interviewer to correct misapprehensions. This will remove significant barriers to communication.

The most commonly accepted definitions of cerebral palsy suggest a brain disorder arising in the perinatal period which damages the motor pathways. This results in abnormalities of tone (and hence posture) and motor control. Explaining that the medical term 'spastic' refers to this increased tone is helpful. Once the lesion is established it is non-progressive, another important concept. Depending on the nature of brain insult, it may be possible to outline the most frequent pattern of cerebral palsy seen with it. Kernicterus and very late perinatal acute asphyxia for instance are both associated with the development of dyskinetic athetoid cerebral palsy. ${ }^{12}$

Written information at this point can be helpful in getting the message across. Some texts are written for parents rather than professionals and can be helpful in allowing the parents to formulate more specific questions. ${ }^{13}$ An outline of any early interventions (such as physiotherapy), their rationale and benefit will be a positive message for the parents. ${ }^{14}$

\section{Planning for the future}

In addition to breaking the bad news, it is important to give some positive message. One concept worth introducing is the plastic nature of the neonatal brain which allows occasional remarkable degrees of functionality to return. The parents' role in aiding this process should be stressed, giving them a positive role as soon as possible. The concept of their child's potential is one that parents accept and grasp readily. Remembering the concept of the range of potential outcomes above, it can be expressed in terms of the number of agencies and people who will help their child over the first few years. Lack of awareness of speciality referrals and community services is perceived badly. ${ }^{10}$

Some services, such as those provided by the family doctor and health visitor, they will already be familiar with. There are also likely to be local or national organisations who have a great deal to offer these families, including counselling as well as practical help. SCOPE, the British organisation dedicated to helping people with cerebral palsy, is one example. The hospital social worker will have a list of contacts for such organisations. 


\section{Enhancing communication}

- listen

- check parents' understanding at each interview

- meet parents several times

- have a nurse present

- ask parents to write down their questions

- use any scans or images or demonstrate physical signs to the parents

Box 5

1 Little WJ. On the influence of abnormal parturition, difficult labours, premature birth, and asphyxia neonatorum, on the mental and physical condition of the child, especially in relation to deformities. Trans Obstet Soc London 1862; 3: 293-344.

2 Levene MI. The asphyxiated newborn infant. In: Levene MI, Bennett MJ, Punt J, eds. Fetal and neonatal neurology and neurosurgery, 1 st edn Edinburgh: Churchill Livingstone, 1988; pp 370-82.

3 Steiner H, Neligan G. Perinatal cardiac arrest: quality of survivors. Arch Dis Child 1975; 50: 596-702.

4 Ergander U, Eriksson M, Zetterstrom R. Severe neonatal asphyxia: incidence and prediction of outcome in the Stockholm area. Acta Paeditr Scand 1983; 72: 321-5.

5 Ventriculomegaly Trial Group. Randomised

Ventriculomegaly Trial Group. Randomised trial of early tapping in neonatal posthaemorr-
hagic ventricular dilatation: results at 30 hagic ventricular dilatation: results at
months. Arch Dis Child 1994; 70: 141-6.

\section{Learning how to do it}

How can you learn or improve the skills needed for this task? The first step is to sit in during a consultation in which bad news is being given. This, as described above, has the potential for training for both the exponent and the observer. A well-defined positive-feedback 'system' is available to ensure that the exponent does not feel threatened. Role play, though seemingly disliked by many, can in the right format be a very effective tool for improving communication skills and raising issues. Texts are also available giving an overview of communication between health professionals and their patients, and used with practical or role-playing experience can help with identifying specific areas for attention and improvement. ${ }^{11}$

In summary the basic communication skills needed in this situation are no different from those used generally. An understanding of parental reaction to the breaking of bad news is helpful. Boxes 2-5 adapted from Krahn $e t$ al, ${ }^{10}$ give a list of parental concerns which informers should attempt to address.

6 Ryan SW. Cranial ultrasound in the newborn. In: Carty H, Shaw D, Brunelle F, Kendall B, eds. Imaging children. 1st edn, Vol 2. Edinburgh: Churchill Livingstone, 1994; pp 1426-39.

7 De Vries LS, Larroche JC, Levene MI. Cerebral ischaemic lesions. In: Levene MI, Bennet $\mathrm{MJ}$, Punt J, eds. Fetal and neonatal neurology and neurosurgery, lst edn. Edinburgh: Churchill Livingstone, 1988; pp 326-38.

8 Gaffney G, Flavell V, Johnson A, Squier M, Sellers S. Cerebral palsy and neonata encephalopathy. Arch Dis Child 1994; 70: F195-200.

9 Naeye RL, Peters EC, Bartholomew M, Landis R. Origins of cerebral palsy. Am $\mathcal{F}$ Dis Child 1989; 143: 1154-61.

10 Krahn GL, Hallum A, Kime C. Are there good ways to give 'bad news'. Pediatrics 1993; 91: ways to

11 Smith VM, Bass TA, eds. Communication for health professionals, 1st edn. Philadelphia: JB Lipincott Company, 1979.
12 Rosenbloom L. Dyskinetic cerebral palsy and birth asphyxia. Dev Med Child Neurol 1994; 36: birth asph.

13 Finnie NR, ed. Handling the young cerebral palsied child at home, 2nd edn. London: William Heinemann Medical, 1981.

14 Scrutton D, ed. Management of the motor disorders of children with cerebral palsy, 1st edn. London: Spastics International Medical Publications, 1984.

\section{Medical Anniversary \\ HENRY HALLETT DALE, 9 JUNE 1875}

(Sir) Henry Hallett Dale (1875-1968) was born in London, son of a cabinet maker. He was educated at Trinity, Cambridge, and St Bartholomew's, London, where he qualified (1909). He became Director of the Wellcome Laboratories and then Director of the National Institute for Medical Research. For his embracing theory of the chemical transmission of nervous impulses, he shared the Nobel Prize (1936) with his friend Otto Loewi. He became FRS (1914), PRS (1942), OM (1944), Kt (1932) and received numerous honours and presidencies. He died on 23 July 1968. 